\title{
Quality and Outcomes of Care
}

\section{Managed Care, Access to Specialists, and Outcomes among Primary Care Patients with Pain}

\author{
David E. Grembowski, Diane Martin, Paula Diehr, Donald L. \\ Patrick, Barbara Williams, Louise Novak, Richard Deyo, Wayne \\ Katon, Deborah Dickstein, Ruth Engelberg, and Harold Goldberg
}

Objective. To determine whether managed care controls were associated with reduced access to specialists and worse outcomes among primary care patients with pain.

Data Sources/Study Setting. Patient, physician, and office manager questionnaires collected in the Seattle area in 1996-1997, plus data abstracted from patient records and health plans.

Study Design. A prospective cohort study of 2,275 adult patients with common pain problems recruited in the offices of 261 primary care physicians in Seattle.

Data Collection. Patients completed a waiting room questionnaire and follow-up surveys at the end of the first and sixth months to measure access to specialists and outcomes. Intensity of managed care controls measured by plan managed care index and benefit/cost-sharing indexes, office managed care index, physician compensation, financial incentives, and use of clinical guidelines.

Principal Findings. A financial withhold for referral was associated with a lower likelihood of referral to a physician specialist, a greater likelihood of seeing a specialist without referral, and a lower patient rating of care from the primary physician. Otherwise, patients in more managed offices and with greater out-of-network plan benefits had greater access to specialists. Patients with more versus less managed care had similar health outcomes, but patients in more managed offices had lower ratings of care provided by their primary physicians.

Conclusions. Increased managed care controls were generally not associated with reduced access to specialists and worse health outcomes for primary care patients with pain, but patients in more managed offices had lower ratings of care provided by their primary physicians.

Key Words. Managed care programs, pain, primary care, specialties (medical), referral, consultation, outcome assessment

As managed care has grown over the past decade, so have concerns that managed care controls reduce access to specialists, which may result in adverse outcomes for patients (Kassirer 1994). Few studies have examined this 
question among primary care patients (Grembowski et al. 1998), particularly those with pain. Up to 65 percent of primary care patients have some pain symptoms (Anderson and Morrison 1989; Kroenke et al. 1994, Kroenke and Jackson 1998), and primary physicians have discretion to treat or to refer such patients to specialists. Pain problems often are a target of managed care cost controls. Almost 80 million Americans report having chronic pain, generating \$65-75 billion in annual health care costs and accounting for more than 550 million lost work days annually (Bonica 1992). With most Americans obtaining their health care through managed care organizations (MCOs), it becomes more important to understand how MCOs control utilization and whether the utilization controls they impose affect health outcomes.

Most studies in this field have compared fee-for-service patients with patients having some type of managed care. Today, this approach is problematic because MCOs are managing both cost and quality in several ways, and there is a continuum of weak-to-strong managed care controls, rather than a sharp dichotomy with fee-for-service care (Grembowski et al. 1998). One way to overcome this problem is to define the strategies used by health plans, medical offices, and physicians to manage costs and improve quality of care (Grembowski et al. 1998, 2000). The number and strength of these strategies indicates the intensity of an organization's managed care controls.

Two competing hypotheses exist regarding the relationship between managed care strategies and access to specialists. First, as the intensity of managed care controls increases, patients are less likely to receive primary physician referrals and to see specialists (Grembowski et al. 1998). Studies with data collected before 1991 generally indicate that gatekeeping, financial withholds for referral, fewer benefits, and greater cost-sharing, and other

Funding support received from the Agency for Healthcare Research and Quality (formerly AHCPR), Grant no. HS06833.

Address correspondence to David E. Grembowski, Ph.D., Professor, Department of Health Services, School of Public Health and Community Medicine, University of Washington, 1959 NE Pacific Street, Box 357660, Seattle, WA 98195-7660. Dr. Grembowski is also with the Center for Cost and Outcomes Research at the University of Washington. All coauthors are with the University of Washington as follows: Diane Martin, Ph.D., Paula Diehr, Ph.D., Donald L. Patrick, Ph.D., M.S.P.H., Barbara Williams, Ph.D., Louise Novak, M.P.H., and Richard Deyo, M.D., M.P.H., are with the Center for Cost and Outcomes Research and the Department of Health Services. Additionally, Dr. Diehr is with the Department of Biostatistics and Dr. Deyo is with the Department of Medicine. Wayne Katon, M.D., is with the Department of Psychiatry. Deborah Dickstein, M.S.P.H., is with the Center for Cost and Outcomes Research. Ruth Engelberg, Ph.D., and Harold Goldberg, M.D., are with the Department of Medicine. 
MCO controls reduce specialist utilization (Martin et al. 1989; Cherkin et al. 1989; Hurley, Freund, and Gage 1991).

The second hypothesis posits that gatekeeping and other managed care controls restrict direct access to specialists, which increases primary physician referrals and reduces patient self-referral to specialists (Kerr et al. 1995). Recent evidence indicates that gatekeeping and MCOs are associated with greater physician referrals (Kikano et al. 2002; Forrest and Reid 1997; Forrest et al. 1999; Franks and Clancy 1997). If patients see specialists with or without a referral at similar rates, managed care controls may not be associated with specialist utilization.

If greater intensity of managed care is associated with less specialist access, it is unclear whether reduced access improves or reduces outcomes (Kassirer 1994; Miller and Luft 1993; Dudley et al. 1998; Hellinger 1998; Carey et al. 1995; Franks, Nutting, and Clancy; 1993; Yelin et al. 1985; Yelin, Shearn, and Epstein 1986; Yelin, Criswell, and Feigenbaum 1996). Previous studies, however, indicate that restricted specialist access is a source of patient dissatisfaction (Dudley et al. 1998; Kerr et al. 1999; Freudenheim 1999; Grumbach et al. 1999).

We therefore sought to determine whether the intensity of managed care is associated with access to specialists and outcomes for primary care patients with pain.

\section{METHODS}

\section{Design and Populations}

In our Physician Referral Study (Grembowski et al. 2000), we invited 832 primary care physicians (family practitioners, general internists, and general practitioners) in private practice at least 50 percent time in the Seattle metropolitan area in 1996-1997 to participate in the study. Of these, 261 physicians (31 percent) in 72 offices consented to participate. Participating physicians and their office managers, as well as a random sample of 300 nonparticipating physicians, were asked to complete self-administered questionnaires at baseline.

Using a longitudinal cohort design, 17,187 English-speaking patients aged 18 and older were screened in the waiting rooms of the offices for two weeks. Of these, 691 patients were ineligible due to age younger than 18, or language, physical, or mental limitations, and 4,107 eligible patients refused to participate. Of the remaining 12,389 patients, 2,275 patients had one of eight 
common, often persistent pain symptoms (back and neck pain, chest pain, abdominal pain, sinus or facial pain, headache or migraine, pain from indigestion/constipation, pain or arthritis in arms/legs/joints, and pelvic pain from female genitourinary problems) (National Centers for Health Statistics 1992). Patients received mail or telephone surveys at one month and at six months to collect personal characteristics and measures of access to specialists and outcomes. Primary care record reviews were performed for 12 months prestudy and 6 months poststudy to collect data on primary care visits and physician referrals.

\section{DEPENDENT VARIABLES}

Physician Referral and Specialist Utilization. Referral by the primary physician for the pain problem was measured through patient report or chart evidence of referral within six months after the waiting-room screen, or baseline. Three binary $(0,1)$ measures were constructed: (1) referral to either a specialist physician (MD/DO) or other ancillary provider, such as a physical therapist, massage therapist, chiropractor, or acupuncturist; (2) referral to a specialist physician; and (3) referral to an ancillary provider.

Specialist utilization, with or without a referral, was measured by patient report of actually seeing a specialist or ancillary provider for the pain problem within six months after enrollment. Three variables, analogous to those used for referral, were constructed. We also measured whether a patient saw a specialist with or without a referral from the primary physician.

Health Outcomes. Health outcomes were assessed through three measures at baseline and each follow-up. The severity of pain symptoms was measured by an 11-point scale indicating the bothersomeness of the pain in the past four weeks, where " 0 " indicated "not bothersome" and "10" indicated "extremely bothersome" (Patrick et al. 1995; Cherkin et al. 1998). Functional health status was measured by the three-item pain interference scale, where " 0 " indicated "no" interference and "10" indicated "unable to carry on activities" (Von Korff et al. 1992). Restricted activity days were measured by the number of days the patient was limited in usual activities due to physical health problems in the past four weeks (Ware et al. 1996). We computed change scores (baseline score minus follow-up score) for each outcome so that bigger, positive scores indicated more improvement. 
Patient Rating of Health Care. Patients rated the health care provided by their primary physicians at the six-month follow-up on a six-point scale of poor (1), fair, good, very good, excellent, and outstanding (6) (Hays et al. 1999).

\section{INDEPENDENT VARIABLES}

Managed Care. Based on our conceptual model of managed care (Grembowski et al. 1998), we identified managed care controls in three settings, or "levels": health plans, primary care offices, and primary physician practices.

For managed care by health plans, we collected information from medical offices and the waiting-room screen to identify each patient's source of health insurance (e.g., a health insurance firm, a self-insured employer, Medicare, or Medicaid), and we collected information for all health plans offered by each source $(n=189$ health plans with 755 benefit and cost-sharing arrangements). Three health plan indexes, each ranging from 0 to 100, were constructed using principal component analysis and plan information. A plan managed care index (where 100 is a highly managed health plan) measured the intensity of provider-oriented controls in a patient's health plan based on the gatekeeping and lock-in provisions of the plan's network, the plan's referral preauthorization requirements, and whether the plan versus the provider was at financial risk. An in-network benefits index measured the benefits (services covered) and cost-sharing (copayments, coinsurance, and deductibles) in a plan's network, where 100 indicates the least out-of-pocket cost for standard benefits when services are delivered by providers in the network. An out-ofnetwork benefits index measured the benefits and cost-sharing outside a plan's network, where 100 indicates the least out-of-pocket cost for standard benefits when services are delivered by providers outside the plan's network. The construction and validity of the indexes were reported elsewhere (Grembowski et al. 2000).

Office managed care was measured through the following controls: utilization management (the office's referral preauthorization requirements); financial incentives (percentage of office revenue from capitation); and whether the office uses referral guidelines or clinical guidelines for specific conditions. Because the office variables were correlated strongly, we created an office managed care index using principal component analysis. A single factor explained 60 percent of the total variation of the five variables; factor loadings were positive and ranged between .62 and .87 . Factor scores were transformed 
to create a $0-100$ office managed care index, where higher scores indicated more managed offices.

Physician managed care was measured by financial incentives (how the primary physician was paid, whether the physician received a bonus or had a financial withhold for referrals) and the number of Agency for Health Care Policy and Research (AHCPR) clinical guidelines read or used by the physician (Bigos et al. 1994; Rush et al. 1993).

Patient Characteristics. Patient variables included age, gender, race, living alone, employment status, education, and annual household income. The number of comorbidities at baseline was assessed using a checklist of 21 comorbid conditions based on the Medical Outcomes Study (Wells et al. 1991). We also measured the context of care, whether the primary physician at baseline was the patient's usual source of care, whether the baseline visit was the patient's first visit with the primary physician for the pain problem, and whether the patient had sought care for the pain problem in the six months before the baseline visit.

\section{DATA ANALYSIS}

Descriptive analyses were performed to understand patterns of referral, specialist utilization, and health.

Associations between the managed care variables and the referral and specialist utilization variables were identified through logistic regression models, which had two forms. In the patient form, we entered patient covariates and a single managed care variable. In total, 64 models were estimated (eight referral and specialist utilization variables times eight managed care variables). The $0-100$ health plan and office indexes were coded in 10-unit increments $(0-9,10-19$, and so forth) to ease interpretation of odds ratios.

Second, because managed care controls do not operate in isolation, we also estimated a full model for each referral and specialist utilization variable containing patient covariates and all of the managed care variables (Forrest et al. 1999; Brach et al. 2000). Due to high correlation between the plan managed care index and out-of-network benefits $(r=-.77 ; p<.001)$, we estimated the models without the out-of-network benefits index, and then reestimated the models with the out-of-network benefits index but without the plan index.

Associations between the managed care variables and change in health status between baseline and the six-month follow-up were identified through 
the same two forms (patient and full) of ordinary least squares regression models. This model also was used to determine the association between managed care variables and patient rating of health care provided by their primary physicians.

Associations between the managed care variables and health outcomes may be influenced by primary care visits and specialist utilization in the sixmonth follow-up period. We repeated the outcome regressions, adding the following measures as endogenous control variables: number of primary care visits for pain in the follow-up period, whether the patient saw only an ancillary provider for pain, and whether the patient saw a specialist physician for pain.

If persons with poor health selected health plans with greater benefits, or less managedness, this selection bias could be confused with an effect of the health plan. We used three methods of accounting for selection bias; all methods adjusted for the covariates mentioned above. First, we estimated propensity scores predicting, for example, the managed care index of the person's health plan from the patient covariates, then separated the patients into low versus high predicted groups at the median, and repeated the regressions in each stratum (Rosenbaum and Rubin 1984). Given reduced sample sizes and power for each group, in each new regression we checked only whether the sign and size of the regression coefficient for the health plan and benefit index of interest were consistent with the original regression coefficient.

Second, using information about all the plans offered by the employer or source of health insurance, we calculated the minimum, maximum, and mean index of the plans offered by the source, and used these descriptive statistics to predict the managed care index of the person's actual insurance plan. Then, we reestimated the basic regressions described above, adjusting also for the expected managed care index of the patient's health plan, based on the source. Third, in another regression we adjusted for the difference between the managed care index of the person's plan and the average index of the plans offered by the employer. In each new regression equation we checked whether the statistical significance and sign of the regression coefficient for the managed care and benefit index of interest were consistent with the original regression coefficient.

Patients were excluded from regression models when data were missing because the patient did not complete the follow-up, information about the patient's health plan was missing, or the patient's physician or office manager did not complete questionnaires. To account for patients with missing data, we 
estimated propensity scores predicting whether a patient was included versus excluded due to missing data, separated the patients into low versus high predicted groups at the median, and repeated regressions for each group.

Models were estimated with $S T A T A^{\complement}$ statistical software (Stata Corporation 1999), using general estimating equations (GEE) to adjust for correlations among patients in the same medical offices.

\section{RESULTS}

About 95 percent of the participating physicians and 96 percent of office managers completed the self-administered questionnaire, and 82 percent of the nonparticipating physicians completed their questionnaires. Participating and nonparticipating physicians had similar referral rates, board certification, and specialty and racial mix, but participants had a higher percentage of group practice and female physicians, fewer years in practice, fewer office hours per week, and fewer patients aged 65 and older, than nonparticipating physicians $(p<.05)$.

About 78 percent of the patients responded to each follow-up, and our analyses are limited to insured patients with complete follow-ups $(n=1,580$; 69 percent of enrolled patients). Patients with complete data were older and had less pain interference with activities than patients without follow-ups. Primary care record reviews were performed for 99 percent of the patients.

Table 1 presents baseline patient characteristics. The average age was 46 years, and most patients were white. There were more females, a majority were married, and patients were educated beyond high school and had moderate family incomes. On average, patients had elevated pain interference and bothersomeness, and were restricted in their usual activities five days in the past month. Musculoskeletal pains were most common, and two-thirds of the patients had two or more comorbid conditions. For most patients, the primary physician at baseline was the usual source of care. About half the patients were seeing their primary physician the first time for their pain symptoms, and a similar percentage had seen a health professional for their pain in the past six months.

Table 2 presents descriptive statistics of the health plan, office, and physician managed care variables for patients. The correlation between the plan managed care index and the office managed care index was .41 $(p=.001)$, indicating that patients with more managed plans were generallybut not always - seen in more managed offices. 
Table 1: Characteristics of Patients with Pain at Waiting Room Screen

\begin{tabular}{|c|c|c|c|c|}
\hline \multirow[b]{2}{*}{ Measure } & \multirow{2}{*}{$\begin{array}{l}\text { Percent or } \\
\text { Average }\end{array}$} & \multicolumn{3}{|c|}{ Percentile Ranges } \\
\hline & & 25 & 50 & 75 \\
\hline \multicolumn{5}{|l|}{ Sociodemographic characteristics } \\
\hline Age & 49 & 37 & 47 & 59 \\
\hline Female & $67 \%$ & & & \\
\hline Nonwhite & $11 \%$ & & & \\
\hline Living alone & $32 \%$ & & & \\
\hline Employed & $65 \%$ & & & \\
\hline Education (years) & 14 & 12 & 13 & 16 \\
\hline Annual household income (\$) & 47,726 & 25,000 & 45,000 & 62,500 \\
\hline \multicolumn{5}{|l|}{ Pain symptoms } \\
\hline Joint, arm, or leg pain & $34 \%$ & & & \\
\hline Back or neck pain & $22 \%$ & & & \\
\hline Sinus, ear, or facial pain & $13 \%$ & & & \\
\hline Abdominal pain & $9 \%$ & & & \\
\hline Headache and migraine & $8 \%$ & & & \\
\hline Chest pain & $7 \%$ & & & \\
\hline Pelvic pain & $3 \%$ & & & \\
\hline Pain from indigestion and constipation & $3 \%$ & & & \\
\hline \multicolumn{5}{|l|}{ Health measures } \\
\hline Depressive symptoms & $33 \%$ & & & \\
\hline Pain interference & 4.84 & 2.3 & 5.0 & 7.3 \\
\hline Pain bothersomeness & 6.64 & 5 & 7 & 9 \\
\hline $\begin{array}{l}\text { Restricted activity days due to physical health in } \\
\text { past four weeks }\end{array}$ & 5.44 & 0 & 2 & 7 \\
\hline Number of comorbidities & 2.53 & 1 & 2 & 4 \\
\hline \multicolumn{5}{|l|}{ Health care context } \\
\hline $\begin{array}{l}\text { Primary care physician at waiting room screen is } \\
\text { patient's usual source of medical care }\end{array}$ & $80 \%$ & & & \\
\hline $\begin{array}{l}\text { Patients seeing primary care physician first time for } \\
\text { pain problem }\end{array}$ & $50 \%$ & & & \\
\hline $\begin{array}{l}\text { Patients with visits to any health professional for } \\
\text { pain problem in past six months }\end{array}$ & $57 \%$ & & & \\
\hline
\end{tabular}

\section{PHYSICIAN REFERRAL AND SPECIALIST UTILIZATION}

Physician referrals and specialist utilization were relatively common (see Table 3). The percentage of patients seeing specialist physicians or ancillary providers was similar. More patients saw specialists through referral than solely without referral. Patients who saw a specialist for pain also had more primary care visits for pain than patients who did not see a specialist ( 2.3 versus 1.6 visits, $p<.001)$. Worse pain at baseline, prior visits to the primary physician 
Table 2: Descriptive Statistics of Managed Care Variables for Health Plans, Primary Care Offices, and Primary Physicians

\begin{tabular}{|c|c|c|c|c|c|}
\hline & \multirow[b]{2}{*}{ Direction $^{1}$} & \multirow[b]{2}{*}{ Average } & \multicolumn{3}{|c|}{ Percentile Ranges } \\
\hline & & & 25 & 50 & 75 \\
\hline \multicolumn{6}{|l|}{ Health Plan Indexes } \\
\hline Plan Managed Care Index & $(-)$ & 38 & 7 & 46 & 63 \\
\hline In-Network Benefits Index & $(+)$ & 90 & 86 & 92 & 97 \\
\hline Out-of-Network Benefits Index & $(+)$ & 44 & 0 & 57 & 73 \\
\hline Office Managed Care Index & & Average & & & \\
\hline Office Managed Care Index ${ }^{2}$ & $(-)$ & 37 & 9 & 22 & 77 \\
\hline Physician Managed Care Variables & & $\begin{array}{l}\text { Percent of Patients } \\
\text { Seeing Primary } \\
\text { Physicians with } \\
\text { These Characteristics }\end{array}$ & & & \\
\hline Payment by salary & $(+)$ & $66 \%$ & & & \\
\hline Productivity bonus & $(+)$ & $54 \%$ & & & \\
\hline Financial withhold for referral & $(-)$ & $32 \%$ & & & \\
\hline $\begin{array}{l}\text { Average number of AHCPR } \\
\text { guidelines read or used }\end{array}$ & (0) & .67 & 0 & 0 & 1 \\
\hline
\end{tabular}

\footnotetext{
$\overline{{ }^{1} \mathrm{~A}(+) \text { indicates the managed care variable is expected to be associated with greater access to }}$ specialists; a $(-)$ indicates lower access; and a $(0)$ indicates either lower or greater access (Grembowski et al. 1998).

${ }^{2}$ The office managed care index was constructed from five measures (Source: office manager survey). Patients were seen in offices that, on average, received $34 \%$ of their revenue from capitation. About $24 \%$ of patients were seen in offices where prior approval from the office's medical director was required before referring the patient to a specialist inside the office. About $61 \%$ of the patients were seen in offices where prior approval was required to refer outside the office, and almost half of the patients were seen in offices with referral guidelines (43\%) or clinical guidelines for specific conditions (43\%).
}

for pain, and prior visits to other health professionals had the strongest associations with referral and specialist utilization.

\section{Health Plan Managed Care}

The plan managed care index and the in-network benefits index had no significant associations with referrals and specialist utilization. The out-ofnetwork benefits index was associated with more referrals. The odds of referral to any type of specialist for pain increased 5 percent for each 10-unit increase in the out-of-network benefits index (odds ratio 1.05; CI 1.003 to 1.09), and the odds of referral to an ancillary provider also increased by the same amount (odds ratio 1.05 ; CI 1.01 to 1.10 ). 
Table 3: Primary Physician Referral and Specialist Utilization Rates at Six-Month Follow-Up (Unadjusted)

Percent of Patients $(n=1,580)$

\begin{tabular}{l}
\hline $\begin{array}{l}\text { Primary physician referral } \\
\text { Percent of patients referred by their primary physician to one or } \\
\text { more specialist physicians or ancillary providers for pain }\end{array}$ \\
$\begin{array}{l}\text { Percent of patients referred by their primary physician to one or } \\
\text { more specialist physicians for pain }\end{array}$ \\
$\begin{array}{l}\text { Percent of patients referred by their primary physician to one or } \\
\text { more ancillary providers for pain }\end{array}$ \\
$\begin{array}{l}\text { Specialist utilization } \\
\text { Percent of patients who saw one or more specialist physicians or } \\
\text { ancillary providers for pain }\end{array}$ \\
$\begin{array}{l}\text { Percent of patients who saw one or more specialist physicians for } \\
\text { pain }\end{array}$ \\
$\begin{array}{l}\text { Percent of patients who saw one or more ancillary providers for } \\
\text { pain }\end{array}$ \\
$\begin{array}{l}\text { Specialist utilization via referral } \\
\text { Percent of patients who saw one or more specialists physicians } \\
\text { or ancillary providers with at least one primary physician } \\
\text { referral }\end{array}$ \\
$\begin{array}{l}\text { Percent of patients who saw one or more specialist physicians or } \\
\text { ancillary providers without any primary physician referrals }\end{array}$ \\
\hline
\end{tabular}

\section{Office Managed Care}

Controlling for patient and managed care variables, the odds of referral to a specialist physician or ancillary provider for pain increased 7 percent for each 10-unit increase of the office managed care index (odds ratio 1.07; 95 percent CI 1.01 to 1.14), and the odds of referral to a specialist physician also increased 7 percent for each 10-unit increase in office managed care (odds ratio 1.07; CI 1.01 to 1.14). Similarly, the odds of seeing a specialist with referral increased 7 percent for each 10-unit increase in office managed care (odds ratio 1.07; CI 1.01 to 1.13$)$.

\section{Physician Managed Care}

If a primary physician had a financial withhold, a patient was less likely to be referred to a specialist physician for pain (odds ratio, $.71 ; 95$ percent CI, .51 to .97 ) but more likely to see a specialist without referral (odds ratio, 1.38; 95 percent CI, 1.02 to 1.86). However, when we controlled for both patient and managed care variables, the two odds ratios were similar but no longer 
significant $(p=.06, .15$, respectively), probably due to fewer patients in the full regression model. The other physician variables were not significant.

\section{HEALTH OUTCOMES}

On average, most patients improved. Average pain interference and bothersomeness scores declined by about 55 percent, while restricted activity days declined 33 percent.

The managed care variables were not associated with the extent of improvement in pain interference, bothersomeness, or restricted activity days in any regression model. Greater primary care visits and seeing specialist physicians or ancillary providers in the follow-up period were associated consistently with worse health outcomes.

\section{PAtient Rating of HeAlTh CARE FROM PRIMARY PHYSICIAN}

Patient rating of health care provided by primary physicians averaged 4.18 $(\mathrm{SD}=1.35)$ at the six-month follow-up. Controlling for patient variables, more managed health plans were associated with lower patient ratings, but this association disappeared when controlling for other managed care variables. Controlling for patient variables, each 10-unit increase of the office managed care index was associated with 0.04 lower patient ratings $(p=.002)$, and the same coefficient $(0.04 ; p=.03)$ was obtained when also controlling for other managed care variables.

Controlling for patient variables, a 10-unit increase in out-of-network benefits was associated with a 0.03 increase in patient ratings of their primary physicians' care $(p=.02)$, but this association was not significant when also controlling for managed care variables. Controlling for patient and managed care variables, a financial withhold for referral was associated with a 0.20 decrease in patient ratings $(p=.037)$.

\section{Selection Bias Due to Plan Choice}

About 58 percent of the patients had a choice of two or more health plans. For the significant health plan indexes, we adjusted for potential selection bias due to choice of health plans using the three regression approaches. In two of the 
three approaches, the out-of-network benefits index was not associated with patient ratings of their primary physician, indicating this association was likely due to selection rather than managed care.

\section{LOSS TO FOLLOW-UP}

Through propensity analyses we identified patients with a low versus high probability of being excluded from regression models due to missing data. We repeated the analyses for the two groups and found regression coefficients with similar signs and sizes.

\section{DISCUSSION}

In our sample of primary care patients with pain, we tested competing hypotheses that greater intensity of managed care controls is associated with a decreased versus increased likelihood of referral and of seeing a specialist physician or ancillary provider. We found that most of the managed care controls were not associated with access to specialists for adult patients with pain. We also found limited support for both hypotheses.

The first hypothesis predicted that as the intensity of managed care controls increases, patients might be less likely to receive primary physician referrals and to see specialists. We found that a financial withhold for referrals was associated with reduced referrals to specialist physicians. Because few other managed care variables were associated with reduced referrals to specialists, these findings suggest that controls are effective when they are referral-specific, financial in nature, and close to the doctor-patient relationship.

In contrast, a financial withhold for referrals was not associated with reduced specialist utilization. However, a financial withhold was associated with a greater likelihood of seeing specialists without referral-suggesting that if referral withholds reduce physician referrals, patients may still obtain specialty care on their own. With similar specialist utilization, a financial withhold was not associated with health outcomes, but a withhold was associated with lower patient ratings of care provided by their primary physicians. The latter finding is troublesome, given that in a 1996 survey of California physicians, a financial withhold for referral also was associated with greater perceived pressures to limit referrals in ways that may compromise care (Grumbach et al. 1998). 
The second hypothesis predicted that by restricting direct access to specialists, gatekeeping and other controls might increase referrals. We found that greater intensity of controls in primary care offices was associated with greater referrals, and patients in more managed offices were more likely to see specialists via referral. These patterns may exist because the more managed offices were often in multispecialty delivery systems, and primary physicians may be relatively free to refer to specialists inside-but not outside-their systems. As a consequence, specialist utilization was similar in more versus less managed care settings (Kikano et al. 2002). Greater out-of-network benefits also were associated with a greater likelihood of referral, particularly to ancillary providers.

In summary, managed care controls that limit access of primary care patients to specialists may be offset by other managed care features that increase access (Udvarhelyi et al. 1991). Consequently, health outcomes were similar in more versus less managed health plans and offices, and across the different types of physician managed care, which is consistent with previous findings (Miller and Luft 1993; Dudley et al. 1998; Hellinger 1998; Carey et al. 1995; Franks, Nutting, and Clancy 1993; Yelin et al. 1985; Yelin, Shearn, and Epstein 1986; Yelin, Criswell, and Feigenbaum 1996). Controlling for primary care visits and specialist utilization for pain in the follow-up period did not alter these findings. In fact, greater primary care visits and specialist utilization were associated with less improvement, which probably occurred because sicker patients were more likely to see specialists, and patients who saw specialists also had more primary care visits.

Finally, the health plan indexes were not associated with patient ratings of care provided by their primary physicians, which is consistent with recent studies (Kikano et al. 2002; Reschovsky and Hargraves 2000). However, greater scores for office managed care and a referral withhold were associated with lower patient ratings of primary physician care, providing additional evidence that controls closer to the patient-physician relationship may compromise care.

Our findings are limited to our sample of mainly middle-income Caucasian adults with pain in the private practices of consenting family practitioners, general internists, and general practitioners in the Seattle area. Primary physicians in small practices were less likely to participate, and our findings may not apply to patients in those settings. Managed care associations may be different for adults with pain who receive care only from specialists.

The Seattle patients had a relatively even distribution of traditional indemnity health plans, preferred provider organizations, point of service 
plans, and health maintenance organizations, and were seen in a variety of primary care organizations, ranging from solo practice to integrated delivery systems. Our findings may not be generalizable to other cities and rural areas with different mixes of managed care and delivery systems.

Patients and physicians were not randomized to health plans and medical offices, so our results may be influenced by selection bias. We assessed selection bias due to choice of health plans, and those results were generally consistent with our basic findings. Patient reports may misclassify whether they saw a specialist with or without referral, which may explain associations between referral withholds and specialist use with or without referral.

Because of the numerous statistical tests, some managed care associations may be due to chance. Adjusting $p$-values using the Hochberg approach (Hochberg and Benjamini 1990), none of the managed care variables were associated with access to specialists in the patient and full regression models. However, the association between the office managed care index and greater referrals $(p=.004)$ was almost below the adjusted alpha (.002) in the patient models. After adjusting alpha levels, the plan and office managed care indexes were still associated with lower patient ratings of care provided by their primary physicians in the patient models, but no associations were significant in the full model, which could be due to fewer patients with complete data from all sources.

We conclude that greater managed care controls were generally not associated with reduced access to specialists for primary care patients with pain; only physician financial withholds were associated with reduced referral to specialist physicians. We found no evidence of adverse health outcomes under managed care, but we detected lower patient ratings of care provided by their primary physicians.

\section{ACKNOWLEDGMENTS}

We wish to thank and acknowledge several people who made important contributions to the study. First and foremost, we wish to thank the patients, physicians, and office managers who participated in the study. Rosie Pavlov, John Tarnai, and Donald Dillman, affiliated with the Social and Economic Sciences Research Center at Washington State University, managed the patient follow-up surveys. Naihua Duan and Stephen Shortell provided consultant support for the selection bias analysis and the design of study instruments, respectively. Amy Roussel, an AHRQ (formerly AHCPR) 
postdoctorate fellow, contributed to all phases of study design and data collection. Cornelia Ulrich designed and processed the physician and office manager questionnaires. Megan Dwight and Tracy Laidley assisted in physician recruitment. Marina Madrid managed patient recruitment in physician offices. Shelby Tarutis, Johnny Jeans, Rick Orsillo, Georgia Galvin, Alisa Katai, Massooma Sherzoi, Kristie Marbut, Kathryn Molinar, and Carolyn Hale supported data collection and study administration. Alice Gronski helped prepare the manuscript.

\section{REFERENCES}

Anderson, O. W., and E. M. Morrison. 1989. "The Worth of Medical Care: A Critical Review." Medical Care Revierw 46 (2): 121-55.

Bigos, S., O. Bowyer, G. Braen, K. Brown, R. Deyo, S. Haldeman, J. L. Hart, E. W. Johnson, R. Keller, D. Kido, M. H. Liang, R. M. Nelson, M. Nordin, B. D. Own, M. H. Pope, R. K. Schwartz, D. H. Stewart, J. Susman, J. J. Triano, L. C. Tripp, D. C. Turk, C. Watts, and J. N. Weinstein. 1994. Acute Low Back Pain Problems in Adults: Clinical Practice Guideline Number 14, AHCPR publication no. 95-0642. Rockville, MD: Agency for Health Care Policy and Research, Public Health Service, U.S. Department of Health and Human Services.

Bonica, J. J. 1992. "Importance of the Problem." In Evaluation and Treatment of Chronic Pain, edited by G. M. Aronoff, pp. xx-xxviii. Baltimore, MD: Williams and Wilkins.

Brach, C., L. Sanches, D. Young, J. Rodgers, H. Harvey, T. McLemore, and I. Fraser. 2000. "Wrestling with Typology: Penetrating the 'Black Box' of Managed Care by Focusing on Health Care System Characteristics." Medical Care Research and Review 57 (2, supplement): 93-115.

Carey, T. S., J. Garrett, A. Jackman, C. McLaughlin, J. Fryer, D. R. Smucker, and the North Carolina Back Pain Project. 1995. "The Outcomes and Costs of Care for Acute Low Back Pain among Patients Seen by Primary Care Practitioners, Chiropractors, and Orthopedic Surgeons." Nerw England Journal of Medicine 333 (14): 913-17.

Cherkin, D. C., R. A. Deyo, M. Battie, J. Steet, and W. Barlow. 1998. “A Comparison of Physical Therapy, Chiropractic Manipulation, and Provision of an Educational Booklet for the Treatment of Patients with Low Back Pain.” New England Journal of Medicine 339 (15): 1021-9.

Cherkin, D. C., L. Grothaus, and E. H. Wagner. 1989. "The Effect of Office Visit Copayments on Utilization in a Health Maintenance Organization.” Medical Care 27 (11): 1036-45.

Dudley, R. A., R. H. Miller, T. Y. Korenbrot, and H. S. Luft. 1998. "The Impact of Financial Incentives on Quality of Care." Milbank Quarterly 76 (4): 649-86. 
Forrest, C. B., G. B. Glade, B. Starfield, A. D. Baker, M. Kang, and R. J. Reid. 1999. "Gatekeeping and Referral of Children and Adolescents to Specialty Care." Pediatrics 104 (1): 28-34.

Forrest, C. B., and R. J. Reid. 1997. "Passing the Baton: HMOs' Influence on Referrals for Specialty Care." Health Affairs 16 (6): 157-62.

Franks, P., and C. M. Clancy. 1997. "Referrals of Adult Patients from Primary Care: Demographic Disparities and Their Relationship to HMO Insurance.” Journal of Family Practice 45 (1): 47-53.

Franks, P., P. A. Nutting, and C. M. Clancy. 1993. "Health Care Reform, Primary Care, and the Need for Research." Journal of the American Medical Association 270 (12): 1449-53.

Freudenheim, M. 1999. "Big HMO to Give Decisions on Care Back to Doctors." New York Times, 9 November, sec. A.

Grembowski, D. E., K. Cook, D. L. Patrick, and A. E. Roussel. 1998. "Managed Care and Physician Referral." Medical Care Research and Review 55 (1): 3-31.

Grembowski, D., P. Diehr, L. C. Novak, A. E. Roussel, D. P. Martin, D. L. Patrick, B. Williams, and C. M. Ulrich. 2000. "Measuring the Managedness and Covered Benefits of Health Plans.” Health Services Research 35 (3): 707-34.

Grumbach, K., D. Osmond, K. Vranizan, D. Jaffe, and Bindman. 1998. "Primary Care Physicians' Experience of Financial Incentives in Managed-Care Systems." Nere England Journal of Medicine 339 (21): 1516-21.

Grumbach, K., J. V. Selby, C. Damberg, A. B. Bindman, C. Quesenberry, A. Truman, and C. Uratsu. 1999. "Resolving the Gatekeeper Conundrum: What Patients Value in Primary Care and Referrals to Specialists." Journal of the American Medical Association 282 (3): 261-6.

Hays, R. D., J. A. Shaul, S. L. Williams, J. E. Lubalin, L. D. Harris-Kojetin, S. F. Sweeney, and P. D. Cleary. 1999. "Psychometric Properties of the CAHPS ${ }^{\circledR} 1.0$ Survey Measures.” Medical Care 37 (3): 22-31.

Hellinger, F. J. 1998. "The Effect of Managed Care on Quality: A Review of Recent Evidence." Archives of Internal Medicine 158 (8): 833-41.

Hochberg, V., and Y. Benjamini. 1990. "More Powerful Procedures for Multiple Significance Testing." Statistics in Medicine 9: 811-8.

Hurley, R. E., D. A. Freund, and B. J. Gage. 1991. "Gatekeeper Effects on Patterns of Physician Use." Journal of Family Practice 32 (2): 167-74.

Kassirer,J. P. 1994. “Access to Specialty Care.” New England Journal of Medicine 331 (17): 1151-3.

Kerr, E. A., B. S. Mittman, R. D. Hays, A. L. Siu, B. Leake, and R. H. Brook. 1995. "Managed Care and Capitation in California: How Do Physicians at Financial Risk Control Their Own Utilization?" Annals of Internal Medicine 123 (7): 500-4.

Kerr, E. A., R. D. Hays, A. Mitchinson, M. Lee, and A. L. Siu. 1999. "The Influence of Gatekeeping and Utilization Review on Patient Satisfaction." Journal of General Internal Medicine 14 (5): 287-96.

Kikano, G. E., C. W. Snyder, E. J. Callahan, M. A. Goodwin, and K. C. Stange. 2002. "A Comparison of Ambulatory Services for Patients with Managed Care and Fee-for-Service Insurance.” America Journal of Managed Care 8 (2): 181-6. 
Kroenke, K., and J. L. Jackson. 1998. "Outcome in General Medical Patients Presenting with Common Symptoms: A Prospective Study with a 2-Week and a 3-Month Follow-up." Family Practice 15 (5): 398-403.

Kroenke, K., R. L. Spitzer, J. Williams, M. Linzer, S. R. Hahn, F. V. deGruy, and D. Brody. 1994. "Physical Symptoms in Primary Care: Predictors of Psychiatric Disorders and Functional Impairment." Archives of Family Medicine 3 (9): 774-9.

Martin, D. P., P. Diehr, K. F. Price, and W. C. Richardson. 1989. "Effect of a Gatekeeper Plan on Health Services Use and Charges: A Randomized Trial." American Journal of Public Health 79 (12): 1628-32.

Miller, R. H., and H. S. Luft. 1993. "Managed Care: Past Evidence and Potential Trends." Frontiers of Health Services Management 9 (3): 3-38.

National Centers for Health Statistics. 1992. "National Ambulatory Medical Care Survey: 1989 Summary." Vital and Health Statistics Series 13 (110): 1-80.

Patrick, D. L., R. A. Deyo, S. J. Atlas, D. E. Singer, A. Chapin, and R. B. Keller. 1995. "Assessing Health-Related Quality of Life in Patients with Sciatica." Spine 20 (17): 1899-1909.

Reschovsky, J. D., and J. L. Hargraves. 2000. "Health Care Perceptions and Experiences." Issue Brief. Center for Studying Health System Change 30: 1-6.

Rosenbaum, P. R., and D. B. Rubin. 1984. "Reducing Bias in Observational Studies Using Subclassification on the Propensity Score (in Applications)." Journal of the American Statistical Association 79 (387): 516-24.

Rush, A. J., W. E. Golden, G. W. Hall, M. Herrera, A. Houston, R. G. Kathol, W. Katon, C. L. Matchett, F. Petty, H. C. Schulberg, G. R. Smith, and G. W. Stuart. 1993. Depression in Primary Care, vols. 1 and 2: Clinical Practice Guideline Number 5. AHCPR Publication No. 93-0551. Rockville, MD: Agency for Health Care Policy and Research, Public Health Service, U.S. Department of Health and Human Services.

St Peter, R. F., M. C. Reed, P. Kemper, and D. Blumenthal. 1999. "Changes in the Scope of Care Provided by Primary Care Physicians." New England Journal of Medicine 341 (26): 1980-5.

Stata Corporation. 1999. STATA statistical/data analysis software (Release 6.0). College Station, TX: Stata Corporation.

Udvarhelyi, I. S., K. Jennison, R. S. Phillips, and A. M. Epstein. 1991. "Comparison of the Quality of Ambulatory Care for Fee-for-Service and Prepaid Plans." Annals of Internal Medicine 115 (5): 394-400.

Von Korff, M., J. Ormel, F. J. Keefe, and S. F. Dworkin. 1992. "Grading the Severity of Chronic Pain." Pain 50: 133-49.

Ware, J.Jr, M. Kosinski, and S. D. Keller. 1996. "A 12-Item Short-form Health Survey: Construction of Scales and Preliminary Tests of Reliability and Validity." Medical Care 34 (3): 220-33.

Wells, K. B., W. Rogers, M. A. Burnam, S. Greenfield, and J. E. Ware. 1991. "How the Medical Comorbidity of Depressed Patients Differs across Health Care Settings: Results from the Medical Outcomes Study." American Journal of Psychiatry 148: 1688-96. 
Yelin, E. H., L. A. Criswell, and P. G. Feigenbaum. 1996. "Health Care Utilization and Outcomes among Persons with Rheumatoid Arthritis in Fee-for-Service and Prepaid Group Practice Settings.” Journal of American Medical Association 276 (13): 1048-53.

Yelin, E. H., C. J. Henke, J. S. Kramer, M. C. Nevitt, M. Shearn, and W. V. Epstein. 1985. "A Comparison of the Treatment of Rheumatoid Arthritis in Health Maintenance Organizations and Fee-for-Service Practices.” New England Journal of Medicine 312 (15): 962-7.

Yelin, E. H., M. A. Shearn, and W. V. Epstein. 1986. "Health Outcomes for a Chronic Disease in Prepaid Group Practice and Fee-for-Service Settings: The Case of Rheumatoid Arthritis." Medical Care 24 (3): 236-47. 